\title{
The Etiology of Prostate Cancer
}

\author{
Keng Lim Ng \\ Urology Department, Frimley Park Hospital, Portsmouth Rd, Frimley, Camberley \\ GU16 7UJ, UK
}

Author for correspondence: Keng Lim Ng, Urology Department, Frimley Park Hospital, Portsmouth Rd, Frimley, Camberley GU16 7UJ, UK. Email: keng.ng@nhs.net

Doi: https://doi.org/10.36255/exonpublications.prostatecancer.etiology.2021

\begin{abstract}
While the exact etiology of prostate cancer remains elusive, various modifiable and unmodifiable risk factors have been suggested as contributing factors. These include age, ethnicity, family history, genetics, obesity, diet, hormones, smoking, alcohol, and certain medications; however, none of these, perhaps with the exception of ethnicity and age, has been conclusively proven to be a definite etiological factor for prostate cancer. Men of black African ancestry are more prone to the disease. The probability of developing prostate cancer increases with age, from $0.005 \%$ in men younger than 39 years of age to $2.2 \%$ in men between 40 and 59 years, and $13.7 \%$ in men between 60 and 79 years. A better understanding of the environmental, genetic, nutritional, hormonal, and molecular landscape that shape the etiology and pathophysiology of prostate cancer will lead to better preventative strategies, enhanced diagnostic pathways, and improved management of the disease. This chapter provides an overview of the current understanding of the etiology of prostate cancer.
\end{abstract}

Keywords: androgens; ethnicity; family history; prostate cancer; risk factors

In: Prostate Cancer. Bott SRJ, Ng KL (Editors). Exon Publications, Brisbane, Australia. ISBN: 978-0-6450017-5-4; Doi: https://doi.org/10.36255/exonpublications.prostatecancer.2021

Copyright: The Authors.

License: This open access article is licenced under Creative Commons Attribution-NonCommercial 4.0 International (CC BY-NC 4.0) https://creativecommons.org/licenses/by-nc/4.0/ 


\section{INTRODUCTION}

Prostate cancer is the most common cancer in men and is the third leading cause of cancer-related mortality after lung and colorectal cancers in Europe (1). The etiology of prostate cancer is multifactorial and remain quite baffling, with numerous modifiable and unmodifiable risk factors associated with its development. Some well-established risk factors include advanced age, positive family history, and African ancestry. However, epidemiological studies based on geographical distribution and ethnic variability of prostate cancer have suggested that environmental factors, lifestyle, and diets can influence the risk of prostate cancer and its progression. Global variations in prostate cancer incidence are well known and is comprehensively discussed in chapter 1 of this book. The high incidence of prostate cancer can also be attributed to the increasing use of prostate specific antigen (PSA) screening, aging population, and better diagnostic modalities. Understanding the etiology, pathophysiology, and natural history of prostate cancer is useful to aid in the diagnosis and better management of this cancer.

\section{AGE}

Age is a well-established risk factor for prostate cancer. Incidence of prostate cancer increases with age. Prostate cancer is rare below the age of 40. This age-related trend is seen globally, both in developed and developing countries (2). PSA screening has led to an earlier age of prostate cancer detection as it has a lead time of approximately 10 years before any symptoms occur. The probability of developing prostate cancer increases from $0.005 \%$ in men younger than 39 years of age to $2.2 \%$ in men between 40 and 59 years, and $13.7 \%$ in men between 60 and 79 years (3). The probability of histological diagnosis of prostate cancer is higher with $50 \%$ of men between 70 and 80 years of age showing histological evidence of malignancy (4). Fortunately, majority of these low grade, low volume histological diagnosis of prostate cancer follows an indolent course without any significant risk of dying from the disease.

\section{FAMILY HISTORY AND GENETIC PREDISPOSITION}

Prostate cancer has an increased heritability. Men with a brother or father diagnosed with prostate cancer have a two to four-fold risk of developing prostate cancer-the risk is higher if a brother is diagnosed (5). The risk attributed to genetic factors increases further with more relatives being affected and earlier age of diagnoses (6). In addition, the Nordic Twin Study of Cancer estimated that the variation of prostate cancer risk among twins attributed to genetic factors was $57 \%$, thus making prostate cancer one of the most heritable cancers (7). Recent studies have also suggested increased risk of prostate cancer in families with familial breast cancer and familial prostate cancer traits. A large prospective study of 37002 men for 16 years in the USA identified that those with familial breast cancer had a $21 \%$ greater risk of prostate cancer overall; family history of prostate 
cancer alone was associated with a $68 \%$ increased risk of total disease and those who were with a family history of both cancers were also at elevated risk (8). One possible explanation for the link between familial breast cancer and increased prostate cancer risk lies in the BRCA gene mutation. Given the link between BRCA and breast cancer, and evidence of increased prostate cancer risk among male BRCA carriers, inherited BRCA mutations may provide one biological mechanism for familial clustering of prostate and breast cancer (6). These results from familial history links further enhance and confirm the role of genetic predisposition from susceptible genes associated with prostate cancer risk which has led to the genome wide association studies (GWAS) in prostate cancer. GWAS have provided greater insight to the genetic predisposition for prostate cancer risk. There are more than 180 independent single nucleotide polymorphisms (SNPs) associated with prostate cancer risk, which account for a third of familial prostate cancer heritability risk $(9,10)$. A review by Benafif et al. (11) showed that prostate cancer genetic susceptibility variants can explain $37.5 \%$ of the familial relative risk of prostate cancer, with approximately 6\% accounting for rare variants (including 2 rare SNPs on $8 q 24$ and HOXB13) and 31.5\% for commonly occurring SNPs. In the largest prostate cancer GWAS and meta-analysis reported by Schumacher et al., 63 novel prostate cancer susceptibility loci were identified bringing the total number of known loci to 167 (12). Armed with this genetic information, better targeted prostate cancer screening programs aimed at those at higher risk groups can be performed utilizing genetic identity information kits. Such screening program can target those who will be at risk of clinically significant prostate cancer and will be able to replace the non-specific PSA screening and avoid unnecessary prostate biopsies. Once prostate cancer is diagnosed, the affected individual genetic profiles can be utilized to predict aggressiveness and progression of disease. Furthermore, individualized targeted therapy can be prepared based on these genetic tumor profiles to enhance the precision of the treatment regimen.

\section{ETHNICITY}

There are ethnic and geographic variations in the incidence of prostate cancer. There is a higher incidence, severity, and mortality rates amongst men of black African descent. In the USA, there is a threefold variability amongst different ethnic/racial groups, with the highest incidence amongst black men of African descent (13). Mortality rates are 2.4 times higher in black men in the USA when compared to white men (14). One observation that could account for these differences in incidence and mortality is the prevalence of multiple prostate cancer genetic risk loci across racial/ethnic groups (15). A review by Rani et al. explained the observations of lower TMPRSS-ERG fusion, PTEN deletion, differential methylation of genes (SNRPN, SHANK2, MST1R, and ABCG5), and up-regulation of MNX1 in men of African descent promoted oncogenesis due to the deletion of such protective tumor suppressor roles. Another chemokine receptor, DARC, found in red blood cells where they remove chemokines from prostate tumor microenvironment, has been shown to be depleted in large proportion of African men, contributing to increased incidence and mortality rates in this ethnic group (16). 


\section{SMOKING AND ALCOHOL}

Among the modifiable risk factors for prostate cancer, smoking has been shown to have an association with prostate cancer incidence and mortality. A meta-analysis of 24 cohort studies by Huncharek et al. revealed that there was no increased risk or incidence of prostate cancer among current smokers, but the risk increased with increasing amount smoked. Furthermore, ex-smokers had increased risk of prostate cancer and heavy smokers had a 24-30\% increase risk of prostate cancer related deaths (17). Previous studies have not been conclusive regarding alcohol consumption and prostate cancer risk. However, a systematic review and metaanalysis of 340 studies noted that there was a significant dose-response relationship between alcohol consumption and prostate cancer risk. The risk increases with increasing volume of alcohol intake when compared to non-drinkers (18). This relationship has implications affecting public health strategies which may reduce the risk of prostate cancer in developed countries.

\section{OBESITY AND METABOLIC SYNDROME}

Obesity and increased body mass index have been associated with numerous cancers including prostate cancer, with increased adiposity leading to increased mortality risk of prostate cancer (19). According to the meta-analysis by Cao and Ma, an increase in $5 \mathrm{~kg} / \mathrm{m}^{2}$ in body mass index led to a $20 \%$ higher risk of prostate cancer mortality (20). Despite that, the underlying mechanisms as to why this is the case remains elusive. Three possible reasons which relate the risk of prostate cancer and obesity are insulin like growth factor 1 (IGF-1), sex hormones, and adipokines (21). Recently, more studies on adipokines, which are chemokines secreted by adipocytes into plasma, have shed some light in this aspect. One of the adipokines is adiponectin which has been studied extensively and implicated in the development and progression of prostate cancer. With increasing obesity, plasma adiponectin concentrations fall, especially in men (22). A meta-analysis by Liao et al., showed that lower concentrations of adiponectin was significantly associated with a greater risk of prostate cancer, with various possible explanatory mechanisms which included anti-inflammatory, anti-proliferative, AMPK, and Wnt signaling pathways (23). Therefore, in future, adiponectin may be a potential biomarker in the diagnosis of prostate cancer.

Metabolic syndrome is a cluster of conditions that include hypertension, hyperglycemia, hypercholesterolemia/ high triglycerides, and excess body fat with increased waist circumference. Metabolic syndrome has been associated with increased risk of common cancers like colorectal and breast cancers. In prostate cancer, metabolic syndrome has been shown to have a slight association with incidence of prostate cancer (OR 1.17) and has a greater association with more aggressive disease and biochemical recurrence (24). This was supported by a study of 8122 men in the REDUCE trial which revealed that having three or more components of metabolic syndrome were significantly associated with a greater risk of higher-grade prostate cancer (25). This finding may suggest that controlling the effects of metabolic syndrome may prevent from aggressive prostate cancer progression. 


\section{PHYSICAL ACTIVITY, DIET, AND NUTRITION}

Numerous studies have shown that there is an inverse relationship between physical activity and risk of progression and mortality from prostate cancer. One large study of 2705 men with prostate cancer revealed a $61 \%$ reduction in risk of prostate cancer-specific mortality in men who had at least three hours of vigorous exercise per week than those who did less than 1 hour per week (26). However, there is no concrete evidence to suggest if increased physical activity or regular physical exercises could reduce the risk of developing prostate cancer.

Diet and nutrition have been implicated in many cancers including prostate cancer. Numerous studies have investigated the association of prostate cancer and what we consume-fat intake, calcium, dairy, lycopenes, soy consumption, selenium, vitamin D, processed food, and Western diets. Consumption of highly processed foods can increase the risk of prostate cancer and conversely, intake of unprocessed/limited processed foods was associated with lower risk of prostate cancer as shown by PROtEuS study (27). This explains why Westernized diet of fast foods, that are highly processed, have a higher association with the incidence of prostate cancer than less processed foods. Regarding vegetarian diet, a recent metaanalysis which included almost 200 men with prostate cancer diagnosis, did not show any significant association between vegetarian diet and prostate cancer risk compared to a non-vegetarian diet (28). Lycopene is a red pigmented carotenoid found in tomatoes and watermelons. A systematic review by Rowles et al. showed that increased dietary and circulating lycopene lowers prostate cancer risk. Higher dietary intake and circulating lycopene levels corresponded to greater reduction in prostate cancer risk (29). Prostate cancer incidence is much lower in Asian countries where soy consumption is high. This has led to numerous studies on soy foods with the isoflavone levels (genistein and daidzein) and its association with prostate cancer. Conclusion from a systematic review by Applegate et al. showed that increased soy food consumption significantly lowers the risk of prostate cancer (30). The SELECT trial (Selenium and Vitamin E Cancer Prevention Trial) did not show any benefit of selenium and vitamin E supplementation in reducing the risk of prostate cancer but in fact increased the risk of high-grade cancer and type 2 diabetes mellitus (31). A Mendelian randomization analysis revealed that selenium supplementation did not enhance prostate cancer prevention, and may lead to increased risk of advanced prostate cancer and type 2 diabetes (32).

Dairy products which contain plenty of calcium have been studied extensively in prostate cancer. Most studies show that there is a positive association between dietary intake of dairy products and intake of high calcium with prostate cancer $(33,34)$. One probable mechanism for this lies in the fact that increased calcium levels will suppress the levels of 1,25 dihydroxyvitamin $\mathrm{D}$ (calcitriol), which is the active form of vitamin D. Calcitriol has been shown to affect cell cycle, induce apoptosis and inhibit the growth of normal prostatic epithelial cells, together with prostate cancer cell lines and primary cultures of prostate cancer cells (35). Dairy products are associated with increased levels of insulin like growth factors which has been linked to high-grade prostate cancer (36). However, the expert report from the World Cancer Research Fund on Diet and Cancer stated that calcium intake is a "probable" risk factor for prostate cancer, but the evidence for dairy products was weak and inconclusive (37). 
Countries where there is higher fish consumption have recorded lower incidence of prostate cancer than countries of Western diet low in fish intake. Various studies looking at fish intake and prostate cancer progression have mixed results, some showing a reduction in risk while others showing no association $(38,39)$. Interestingly, Richman et al. showed that consumption of eggs and poultry with skin following diagnosis of prostate cancer, may increase the risk of prostate cancer progression (39).

Due to the abundance of literature on diet, nutrition, weight, exercise, and its association with prostate cancer, one can only be practical in the approach to reduce the risk of prostate cancer. Therefore, for those who are concerned with prostate cancer risk, Wilson et al. have recommended to stop smoking, increase physical activities, and observe a healthy weight. The authors have also recommended increasing fish and tomatoes intake while reducing dairy intake (40). The 2018 World Cancer Research Fund/American Institute for Cancer Research Cancer Prevention Recommendations and Prostate Cancer revealed that three componentslimiting the consumption of sugary drinks, heavily processed foods, and alcoholhave been independently associated with lowering prostate cancer risk (41).

\section{MEDICATIONS}

Metformin has been the cornerstone of treatment of type 2 diabetes mellitus for a long time, but recent interest has shed light on its anti-neoplastic properties, particularly in prostate cancer patients. In a comprehensive review by Ahn et al., there were numerous studies that showed metformin usage associated with reduction in risk of prostate cancer and progression, while other studies noted no association regarding incidence or survival. Various antineoplastic mechanisms of metformin involving numerous pathways like adenosine monophosphateactivated protein kinase (AMPK) activation, inhibition of the mammalian target of rapamycin (mTOR) activity and induction of apoptosis have been shown (42). In a recent meta-analysis of cohort studies investigating metformin use and prostate cancer risk, there was no association noted (43). Nonetheless, there are currently ongoing clinical trials investigating the use of metformin monotherapy, or in conjunction with androgen deprivation therapy, in metastatic prostate cancer patients, hoping to shed some light for the use of metformin in improving prostate cancer survival. Statins have also been implicated in delaying the progression of prostate cancer. In a large study of 11,000 prostate cancer patients in the United Kingdom, post-diagnostic patients who had statins showed a 34\% lower risk of prostate cancer death (44). Furthermore, this effect was even stronger for men who were already on statins prior to diagnosis. Another retrospective study revealed that the time to progression was longer in patients who were on anti-androgen therapy and statins compared to those who were not on statins (45).

\section{SEX AND VASECTOMY}

Interestingly, the meta-analysis by Jian et al. showed that the risk of prostate cancer decreases by $4 \%$ for every 5 years delay in the age of first sexual intercourse. 
The authors also concluded that an increment of 10 female sexual partner is associated with a 1.1-fold increase in prostate cancer risk. Moderate ejaculation frequency (2-4 times/week) was also significantly associated with lower risk of prostate cancer (46). Another aspect of ejaculation regarding vasectomy has also been implicated in prostate cancer risk. A systematic review by Bhindi et al. showed that there was no association between vasectomy and prostate cancer risk (47).

\section{HORMONES}

Initial studies decades ago, described the close relationship of testosterone/ androgens to prostate growth, and has led to anti-androgen treatment as one of the corner stone of metastatic prostate cancer treatment. However, over the last few years there has been a paradigm shift in our understanding, attitude, and application of testosterone to prostate cancer risk, progression, and survival. The mechanism of androgen receptor saturation model described by Morgentaler et al. showed that in the prostate, anything above the baseline serum testosterone concentration will play no further role in stimulating prostate growth, due to the fact that the intraprostatic androgen receptor sites are completely saturated/ bound (48).

A recent review by Golla et al. analyzed data from studies investigating the use of testosterone in localized prostate cancer on active surveillance, watchful waiting, and definitive treatments. They found that there was no increased risk of prostate cancer diagnosis or more aggressive cancer at diagnosis in men with testosterone supplementation for testosterone deficiency. They also concluded that there is no increased risk of cancer progression in men who are on active surveillance and definitive treatment with testosterone therapy (49).

Regarding 5 alpha reductase inhibitors (5ARIs) and its association with prostate cancer, the two initial studies (PCPT and REDUCE trials) paved way to our understanding of 5ARI in relation to treatment of lower urinary tract symptoms caused by benign prostatic hyperplasia and risk of prostate cancer. 5ARIs prevent the conversion of testosterone to dihydrotestosterone which is the active hormone that regulates growth in prostate cells. In both trials, there was significant risk reduction (22-24\%) in developing prostate cancer, but there was increased risk of high-grade prostate cancer at diagnosis $(50,51)$. However, there were explanations later following further sub analysis that accounted for the increased risk of high-grade disease.

Furthermore, two large studies confirmed the effectiveness of 5ARIs in reducing the risk of developing prostate cancer. Unger et al. showed that in 16-year follow-up, there was $21.1 \%$ decreased risk of prostate cancer in men who had finasteride compared with placebo and suggested that short term, seven-years, usage of finasteride could provide long term benefit in preventing prostate cancer (52). This finding was further supported by another study in Sweden in which 23,442 men who had treatment with 5ARls for eight years resulted in reduction in the overall risk of developing prostate cancer, and the effect was larger with longer drug exposure. It also revealed that 5ARI treatment did not affect the long-term risk of developing high-grade cancer at diagnosis (53). 


\section{INFECTION, INFLAMMATION AND CHEMOKINES}

Chronic inflammation is often a result of numerous exogenous stimuli like infections, radiation, hormones, chemicals, and other noxious stimuli. Following on from this, cancers can often be a subsequent chain of events related chronic inflammation. The key feature of cancer-related inflammation is the recruitment of leukocytes, production of cytokines and chemokines, and subsequent progression, angiogenesis, epithelial-mesenchymal transition (EMT), migration, and metastasis (54). Prostate cancer is no different and numerous studies have investigated the role of chemokines produced by cancer cells and prostate cancer-related chronic inflammation pathway. Chemokines are chemotactic cytokines that influence immune responses and inflammation (54). These inflammatory milieus will then interact with the tumor microenvironment and can lead to development and progression of the tumor. Examples of such important chemokines in prostate cancer are CXCR - upregulated in prostate cancer, and DARC — absence of which will lead to increased incidence and mortality of prostate cancer (16). Better understanding of chemokines and its receptor axis in the tumor microenvironment will pave way for future chemokine targeted therapies in prostate cancer.

\section{CONCLUSION}

In summary, although there are many putative risk factors for prostate cancer, apart from ethnicity and age, there is no confirmative etiological factor. Even with age, the frequent use of imaging modalities for other causes resulting in increased incidental finding of prostate cancer in younger men appear to cast doubt on the role of age being a risk factor. While a family history of prostate cancer helps early monitoring of susceptible individuals, more studies need to be done to ascertain the true role of family history in prostate cancer. Results of studies suggesting the role of smoking, alcohol, diet, physical activity, and other non-genetic factors being risk factor for prostate cancer are equivocal. GWAS have great potential, and the identification of SNPs may enable a specific screening program replacing the non-specific PSA screening and avoid unnecessary prostate biopsies.

Conflict of interest: The author declares no potential conflicts of interest with respect to research, authorship and/or publication of this article.

Copyright and permission statement: The author confirms that the materials included in this chapter do not violate copyright laws. Where relevant, appropriate permissions have been obtained from the original copyright holder(s), and all original sources have been appropriately acknowledged or referenced.

\section{REFERENCES}

1. Bray F, Ferlay J, Soerjomataram I, Siegel RL, Torre LA, Jemal A. Global cancer statistics 2018: GLOBOCAN estimates of incidence and mortality worldwide for 36 cancers in 185 countries. CA Cancer J Clin. 2018;68(6):394-424. https://doi.org/10.3322/caac.21492 
2. Ferlay J, Soerjomataram I, Dikshit R, Eser S, Mathers C, Rebelo M, et al. Cancer incidence and mortality worldwide: sources, methods and major patterns in GLOBOCAN 2012. Int J Cancer. 2015;136(5):E359-86. https://doi.org/10.1002/ijc.29210

3. Newcomer LM, Stanford JL, Blumenstein BA, Brawer MK. Temporal trends in rates of prostate cancer: declining incidence of advanced stage disease, 1974 to 1994. J Urol. 1997;158(4):1427-30. https:// doi.org/10.1016/S0022-5347(01)64231-9

4. Carter HB, Piantadosi S, Isaacs JT. Clinical evidence for and implications of the multistep development of prostate cancer. J Urol. 1990;143(4):742-6. https://doi.org/10.1016/ S0022-5347(17)40078-4

5. Kalish LA, McDougal WS, McKinlay JB. Family history and the risk of prostate cancer. Urology. 2000;56(5):803-6. https://doi.org/10.1016/S0090-4295(00)00780-9

6. Chen YC, Page JH, Chen R, Giovannucci E. Family history of prostate and breast cancer and the risk of prostate cancer in the PSA era. Prostate. 2008;68(14):1582-91. https://doi.org/10.1002/ pros. 20825

7. Mucci LA, Hjelmborg JB, Harris JR, Czene K, Havelick DJ, Scheike T, et al. Familial Risk and Heritability of Cancer Among Twins in Nordic Countries. JAMA. 2016;315(1):68-76. https://doi. org/10.1001/jama.2015.17703

8. Barber L, Gerke T, Markt SC, Peisch SF, Wilson KM, Ahearn T, et al. Family History of Breast or Prostate Cancer and Prostate Cancer Risk. Clin Cancer Res. 2018;24(23):5910-7. https://doi. org/10.1158/1078-0432.CCR-18-0370

9. Amin Al Olama A, Dadaev T, Hazelett DJ, Li Q, Leongamornlert D, Saunders EJ, et al. Multiple novel prostate cancer susceptibility signals identified by fine-mapping of known risk loci among Europeans. Hum Mol Genet. 2015;24(19):5589-602. https://doi.org/10.1093/hmg/ddv203

10. Hooker S, Hernandez W, Chen H, Robbins C, Torres JB, Ahaghotu C, et al. Replication of prostate cancer risk loci on 8q24, 11q13, 17q12, 19q33, and Xpll in African Americans. Prostate. 2010;70(3):270-5. https://doi.org/10.1002/pros.21061

11. Benafif S, Kote-Jarai Z, Eeles RA, Consortium P. A Review of Prostate Cancer Genome-Wide Association Studies (GWAS). Cancer Epidemiol Biomarkers Prev. 2018;27(8):845-57. https://doi. org/10.1158/1055-9965.EPI-16-1046

12. Schumacher FR, Al Olama AA, Berndt SI, Benlloch S, Ahmed M, Saunders EJ, et al. Association analyses of more than 140,000 men identify 63 new prostate cancer susceptibility loci. Nat Genet. 2018;50(7):928-36. https://doi.org/10.1038/s41588-018-0142-8

13. Pernar CH, Ebot EM, Wilson KM, Mucci LA. The Epidemiology of Prostate Cancer. Cold Spring Harb Perspect Med. 2018;8(12). https://doi.org/10.1101/cshperspect.a030361

14. Howlader N, Noone A, Krapcho M, Miller D, Bishop K. SEER Cancer Statistics Review 1975-2013. National Cancer Institute, Bethesda MD; 2016.

15. Haiman CA, Chen GK, Blot WJ, Strom SS, Berndt SI, Kittles RA, et al. Characterizing genetic risk at known prostate cancer susceptibility loci in African Americans. PLoS Genet. 2011;7(5):e1001387. https://doi.org/10.1371/journal.pgen.1001387

16. Rani A, Dasgupta P, Murphy JJ. Prostate Cancer: The Role of Inflammation and Chemokines. Am J Pathol. 2019;189(11):2119-37. https://doi.org/10.1016/j.ajpath.2019.07.007

17. Huncharek M, Haddock KS, Reid R, Kupelnick B. Smoking as a risk factor for prostate cancer: a meta-analysis of 24 prospective cohort studies. Am J Public Health. 2010;100(4):693-701. https:// doi.org/10.2105/AJPH.2008.150508

18. Zhao J, Stockwell T, Roemer A, Chikritzhs T. Is alcohol consumption a risk factor for prostate cancer? A systematic review and meta-analysis. BMC cancer. 2016;16(1):845. https://doi.org/10.1186/ s12885-016-2891-z

19. Ma J, Li H, Giovannucci E, Mucci L, Qiu W, Nguyen PL, et al. Prediagnostic body-mass index, plasma C-peptide concentration, and prostate cancer-specific mortality in men with prostate cancer: a long-term survival analysis. Lancet Oncol. 2008;9(11):1039-47. https://doi.org/10.1016/ S1470-2045(08)70235-3

20. Cao Y, Ma J. Body mass index, prostate cancer-specific mortality, and biochemical recurrence: a systematic review and meta-analysis. Cancer Prev Res. 2011;4(4):486-501. https://doi.org/10.1158/19406207.CAPR-10-0229 
21. Smith LA, O'Flanagan CH, Bowers LW, Allott EH, Hursting SD. Translating Mechanism-Based Strategies to Break the Obesity-Cancer Link: A Narrative Review. J Acad Nutr Diet. 2018;118(4):652-67. https:// doi.org/10.1016/j.jand.2017.08.112

22. Saunders TJ, Palombella A, McGuire KA, Janiszewski PM, Després JP, Ross R. Acute exercise increases adiponectin levels in abdominally obese men. J Nutr Metab. 2012;2012:148729. https://doi. org/10.1155/2012/148729

23. Liao Q, Long C, Deng Z, Bi X, Hu J. The role of circulating adiponectin in prostate cancer: a metaanalysis. Int J Biol Markers. 2015;30(1):e22-31. https://doi.org/10.5301/jbm.5000124

24. Gacci M, Russo GI, De Nunzio C, Sebastianelli A, Salvi M, Vignozzi L, et al. Meta-analysis of metabolic syndrome and prostate cancer. Prostate Cancer Prostatic Dis. 2017;20(2):146-55. https://doi. org/10.1038/pcan.2017.1

25. Sourbeer KN, Howard LE, Andriole GL, Moreira DM, Castro-Santamaria R, Freedland SJ, et al. Metabolic syndrome-like components and prostate cancer risk: results from the Reduction by Dutasteride of Prostate Cancer Events (REDUCE) study. BJU Int. 2015;115(5):736-43. https://doi. org/10.1111/bju. 12843

26. Kenfield SA, Stampfer MJ, Giovannucci E, Chan JM. Physical activity and survival after prostate cancer diagnosis in the health professionals follow-up study. J Clin Oncol. 2011;29(6):726-32. https://doi.org/10.1200/JCO.2010.31.5226

27. Trudeau K, Rousseau MC, Parent M. Extent of Food Processing and Risk of Prostate Cancer: The PROtEuS Study in Montreal, Canada. Nutrients. 2020;12(3). https://doi.org/10.3390/ nul2030637

28. Godos J, Bella F, Sciacca S, Galvano F, Grosso G. Vegetarianism and breast, colorectal and prostate cancer risk: an overview and meta-analysis of cohort studies. J Hum Nutr Diet. 2017;30(3):349-59. https://doi.org/10.1111/jhn.12426

29. Rowles JL, Ranard KM, Smith JW, An R, Erdman JW. Increased dietary and circulating lycopene are associated with reduced prostate cancer risk: a systematic review and meta-analysis. Prostate Cancer Prostatic Dis. 2017;20(4):361-77. https://doi.org/10.1038/pcan.2017.25

30. Applegate CC, Rowles JL, Ranard KM, Jeon S, Erdman JW. Soy Consumption and the Risk of Prostate Cancer: An Updated Systematic Review and Meta-Analysis. Nutrients. 2018;10(1). https://doi. org/10.3390/nu10010040

31. Lippman SM, Klein EA, Goodman PJ, Lucia MS, Thompson IM, Ford LG, et al. Effect of selenium and vitamin $\mathrm{E}$ on risk of prostate cancer and other cancers: the Selenium and Vitamin E Cancer Prevention Trial (SELECT). JAMA. 2009;301(1):39-51. https://doi.org/10.1001/jama.2008.864

32. Yarmolinsky J, Bonilla C, Haycock PC, Langdon RJQ, Lotta LA, Langenberg C, et al. Circulating Selenium and Prostate Cancer Risk: A Mendelian Randomization Analysis. J Natl Cancer Inst. 2018;110(9):1035-8. https://doi.org/10.1093/jnci/djy081

33. Park Y, Leitzmann MF, Subar AF, Hollenbeck A, Schatzkin A. Dairy food, calcium, and risk of cancer in the NIH-AARP Diet and Health Study. Arch Intern Med. 2009;169(4):391-401. https://doi. org/10.1001/archinternmed.2008.578

34. Allen NE, Key TJ, Appleby PN, Travis RC, Roddam AW, Tjønneland A, et al. Animal foods, protein, calcium and prostate cancer risk: the European Prospective Investigation into Cancer and Nutrition. Br J Cancer. 2008;98(9):1574-81. https://doi.org/10.1038/sj.bjc.6604331

35. Feldman D, Zhao XY, Krishnan AV. Vitamin D and prostate cancer. Endocrinology. 2000;141(1):5-9. https://doi.org/10.1210/endo.141.1.7341

36. Chan JM, Stampfer MJ, Ma J, Gann P, Gaziano JM, Pollak M, et al. Insulin-like growth factor-I (IGF-I) and IGF binding protein-3 as predictors of advanced-stage prostate cancer. J Natl Cancer Inst. 2002;94(14):1099-106. https://doi.org/10.1093/jnci/94.14.1099

37. Wiseman M. The second World Cancer Research Fund/American Institute for Cancer Research expert report. Food, nutrition, physical activity, and the prevention of cancer: a global perspective. Proc Nutr Soc. 2008;67(3):253-6. https://doi.org/10.1017/S002966510800712X

38. Chan JM, Holick CN, Leitzmann MF, Rimm EB, Willett WC, Stampfer MJ, et al. Diet after diagnosis and the risk of prostate cancer progression, recurrence, and death (United States). Cancer Causes Control. 2006;17(2):199-208. https://doi.org/10.1007/s10552-005-0413-4 
39. Richman EL, Stampfer MJ, Paciorek A, Broering JM, Carroll PR, Chan JM. Intakes of meat, fish, poultry, and eggs and risk of prostate cancer progression. Am J Clin Nutr. 2010;91(3):712-21. https://doi. org/10.3945/ajen.2009.28474

40. Wilson KM, Mucci LA. Diet and Lifestyle in Prostate Cancer. Adv Exp Med Biol. 2019;1210:1-27. https://doi.org/10.1007/978-3-030-32656-2_1

41. Olmedo-Requena R, Lozano-Lorca M, Salcedo-Bellido I, Jiménez-Pacheco A, Vázquez-Alonso F, García-Caballos M, et al. Compliance with the 2018 World Cancer Research Fund/American Institute for Cancer Research Cancer Prevention Recommendations and Prostate Cancer. Nutrients. 2020;12(3).

42. Ahn HK, Lee YH, Koo KC. Current Status and Application of Metformin for Prostate Cancer: A Comprehensive Review. Int J Mol Sci. 2020;21(22). https://doi.org/10.3390/ijms21228540

43. Feng Z, Zhou X, Liu N, Wang J, Chen X, Xu X. Metformin use and prostate cancer risk: A metaanalysis of cohort studies. Medicine (Baltimore). 2019;98(12):el4955. https://doi.org/10.1097/ MD.00000000000014955

44. Yu O, Eberg M, Benayoun S, Aprikian A, Batist G, Suissa S, et al. Use of statins and the risk of death in patients with prostate cancer. J Clin Oncol. 2014;32(1):5-11. https://doi.org/10.1200/ JCO.2013.49.4757

45. Harshman LC, Wang X, Nakabayashi M, Xie W, Valenca L, Werner L, et al. Statin Use at the Time of Initiation of Androgen Deprivation Therapy and Time to Progression in Patients With Hormone-Sensitive Prostate Cancer. JAMA Oncol. 2015;1(4):495-504. https://doi.org/10.1001/ jamaoncol.2015.0829

46. Jian Z, Ye D, Chen Y, Li H, Wang K. Sexual Activity and Risk of Prostate Cancer: A Dose-Response Meta-Analysis. J Sex Med. 2018;15(9):1300-9. https://doi.org/10.1016/j.jsxm.2018.07.004

47. Bhindi B, Wallis CJD, Nayan M, Farrell AM, Trost LW, Hamilton RJ, et al. The Association Between Vasectomy and Prostate Cancer: A Systematic Review and Meta-analysis. JAMA Intern Med. 2017;177(9):1273-86. https://doi.org/10.1001/jamainternmed.2017.2791

48. Morgentaler A, Traish AM. Shifting the paradigm of testosterone and prostate cancer: the saturation model and the limits of androgen-dependent growth. Eur Urol. 2009;55(2):310-20. https://doi. org/10.1016/j.eururo.2008.09.024

49. Golla V, Kaplan AL. Testosterone Therapy on Active Surveillance and Following Definitive Treatment for Prostate Cancer. Curr Urol Rep. 2017;18(7):49. https://doi.org/10.1007/s11934-017-0695-6

50. Thompson IM, Goodman PJ, Tangen CM, Lucia MS, Miller GJ, Ford LG, et al. The influence of finasteride on the development of prostate cancer. N Engl J Med. 2003;349(3):215-24. https://doi. org/10.1056/NEJMoa030660

51. Andriole GL, Bostwick DG, Brawley OW, Gomella LG, Marberger M, Montorsi F, et al. Effect of dutasteride on the risk of prostate cancer. N Engl J Med. 2010;362(13):1192-202. https://doi.org/10.1056/ NEJMoa0908127

52. Unger JM, Hershman DL, Till C, Tangen CM, Barlow WE, Ramsey SD, et al. Using Medicare Claims to Examine Long-term Prostate Cancer Risk of Finasteride in the Prostate Cancer Prevention Trial. J Natl Cancer Inst. 2018;110(11):1208-15. https://doi.org/10.1093/jnci/djy035

53. Wallerstedt A, Strom P, Gronberg H, Nordstrom T, Eklund M. Risk of Prostate Cancer in Men Treated With 5 $\alpha$-Reductase Inhibitors-A Large Population-Based Prospective Study. J Natl Cancer Inst. 2018;110(11):1216-21. https://doi.org/10.1093/jnci/djy036

54. Hughes CE, Nibbs RJB. A guide to chemokines and their receptors. FEBS J. 2018;285(16):2944-71. https://doi.org/10.1111/febs.14466 
